International Journal of Scholarly Papers for Media and Society Research

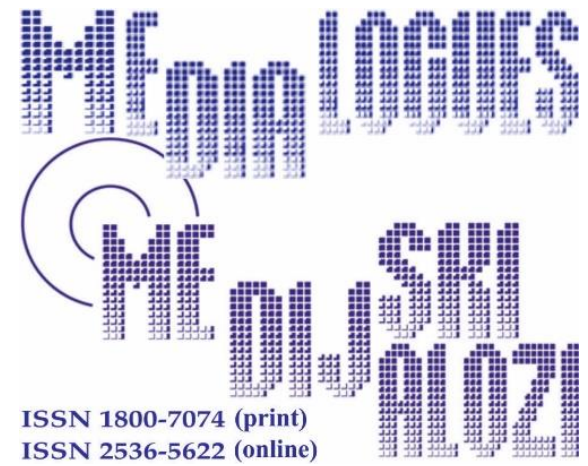

Markovic, B. (2013), „Ethics in Media: Macedonian Case”, Media Dialogues / Medijski dijalozi, Vol. 14, No. 2, pp. 63-74.

\title{
Ethics in Media: Macedonian Case
}

\author{
BRANKA MARKOVIC, MA
}

Political Management Ipsos Adria,

Skopje, Makedonija

\begin{tabular}{|c|c|l|}
\hline $\boldsymbol{A} \boldsymbol{R} \boldsymbol{T} \boldsymbol{I} \boldsymbol{C L} \boldsymbol{E}$ & Received: November 11,2021 / Revised from: December 12, 2021 \\
$\boldsymbol{I} \boldsymbol{N} \boldsymbol{F} \boldsymbol{O}$ & Accepted: January 12, 2021 / & Available online: April 15, 2021 \\
\hline $\boldsymbol{D O I}$ & doi.org/10.14254/1800-7074/14-2/4 \\
\hline
\end{tabular}

\begin{abstract}
This paper discusses the issue of ethics in the Media. It specifically diverts attention to the three core ethical values in Media, the credibility, in-tegrity and civility. It points to the outmost necessity and sanctity of those values and the lack there of in the world today. Media is of great importance to the society since it provides several vital functions. As key functions of media we will emphasize the educational, informational, correlation, criticism and control function and the function of increasing social cohesion by promoting good moral values. Of course its functions depend on the political system of the society in question, but here we are discussing in a context of today's democratic societies. The real world ethical issues in Media
\end{abstract}


are observed trough the case of Macedonia and real examples of the violations of the ethical code of journalism and the credibility, integrity and civility of the Media. Among other most common ethical issues and violations in Macedonian Media are the disregard for peoples sorrow and privacy, publishing of false or unconfirmed information, names or age, in pursuit of sensationalistic broadcasting, publishing full names or unconfirmed information relating to minors and adults suspects of the crime involving minors, including photographs and names of the child victims, disregard for the rule of presumption of innocence, hate speech and stereotyping about minority or vulnerable groups, hate speech based on ethnic and political grounds and etc. As final this paper points to the outcome of such politics of the Macedonian Media and drop of the peoples trust in this vital part of the society.

KEYWORDS: Ethic, media, communications, Macedonia

\section{INTRODUCTION}

Ethics is of outmost concern for every individual's life, for the life of the collectives, the life of the societies and the world in general. One may ask why that is. There is a simple answer: Ethics and ethical behavior provide guidance for making every day decisions ensuring maximum satisfaction and fairness in the long run. We live in an age where globalization makes most if not all social, economic, environmental and other processes intervened which implies that our actions no matter how simple may have larger consequences. This without doubt goes for the media as well.

Media connects the world in a global society. No longer local news stay local, in a matter of hours a news from Singapore reaches Japan, Australia, USA, Africa, the EU and etc. Today news circles the world faster than before and media eyes are interested in all areas of the world and their affairs. Lead by the appeal of sensationalism and the desire to increase circulation and viewer ratings, journalists and Media seldom stop to consider the moral dilemmas and outcomes of their actions. Media can cause panic, harm or even a war but on the other hand it has a great potential to promote good, social cohesion and influence peace. Media has great power and it's in the hands of the people and their moral values to shape and use it right or to their own selfish interests.

This paper is concerned with the ethical aspect of the Media which will be discussed trough four fundamental ethical values in media: credibility, integrity, civility and responsibility. It is so because, "today the media have an irreplaceable role in the modern democratic and pluralistic society. They are one of the factors that actually allow its functioning. Even after the fact that in these societies has come to the relativising of all values, again the question of ethical values and criteria by which the events in the world of societal communication can be and should be run and valued has been brought up" (Donev, 2011, s. 154). 


\section{FUNCTIONS OF THE MEDIA}

More than often in Media studies the roles or functions of Media are discussed. From all the theorized roles of the Media we can all agree on several key functions that Media have in our societies. As key functions we will emphasize the educational, informational, correlation, criticism and control and the function of increasing social cohesion by promoting good moral values. Of course its functions depend on the political system of the society in question, but here we are discussing in a context of today's democratic societies.

The Media is responsible for surveying all aspects of human life and relaying the gathered information to the public in a simplified manner in order to provide the necessary information for the society to function normally. It provides information about the economy, ecology, politics, social life, culture and etc. Today people get day to day information mostly trough Media no matter if it is social media, print media or broadcast media. It also serves as a means of spreading political agenda to the public in pre election and election time and to promote a policy for which the government or political entity will later seek approval. This can be said to be the informational role.

Media trough educational and cultural programs, columns and the like, provides both educational and the role of social glue meaning it increases social cohesion by promoting good values. The Media has great influence on the people since it is a means for the people to get informed and entertained. Young people are easily influenced by it and more often than not it is said that it has a bad influence on the youth by broadcasting movies containing violence and vice and reality shows. But it can also be said that news reports of violent events also have the same influence. No matter the bad influence it can't be denied that trough programs about culture, music, science and the etc Media integrates good values in the minds of the youth.

Media serves as a link between the government and the people. Through it the government can express their opinions on an issue or give response on an issue the public is concerned about, promote their policies and rally support. At the same time the public can communicate to the government their concerns and express their support. This is the correlation function. Medias' function is not to manipulate the public opinion even though it has that power.

Also one of the fundamental functions of media is the function of criticism and control of the government. The Media is responsible to oversee the work of the government and to react when it's not doing the job right. It oversees the governments work and policies about the economy, social policies, Medicare and the like. Ideally the media with the public opinion can influence the government and help shape their policies to best fit the needs of the people. 


\section{ETHICAL VALUES IN THE MEDIA}

What is morality? What is ethics? Is there a difference?

Before any further discussion can be made we need to observe the two terms ethics and morality and compare them. The term "morality" comes from the Latin word mores which means a custom, habit or a way of life. It is used to explain what is good, righteous, appropriate, honorable and just. On the other hand the term "ethics" comes from the Greek word ethos which means a custom, tradition or a way of con- duct. Due to their obvious similarity in meaning they are often used as synonyms. But there is a difference between the two terms.

"They represent separate elements of normative analysis: morality refers to values and beliefs about what is right and wrong, good and bad, just and unjust, and ethics refers to anal-ysis, justification and critical analysis of moral" (Amstuc, 2008, s. 22).

For the purpose of this paper they will be used as synonyms.

It is critical to mention that moral values have 3 dimensions (Ibid., ss. 22-23):

- everyone should obey them;

- they call for impartiality;

- they enforce themselves in great deal.

The notion that everyone should obey them gives morality and moral values its universality. It means that if one moral imperative is compulsory for person A it is also compulsory for person B or their collective. In regards to the call for impartiality it can be said that it provides ground for justice, puts own self interest and selfishness aside and makes morality personally and socially desirable. The third dimension of morality, to enforce themselves, comes from the beliefs and values which are freely chosen by the people, which means they are obeyed not because of existence of laws but by peoples own free will.

Morality implies taking into consideration the interests of others when making our decisions and acting on them. Being moral starts with the individual and from personal moral code it transfers into the professional and public life of the individual. In a world where moral values are slowly forgotten in order to get to the desired goals faster change must happen at an individual level.

There are many ethical values in the ethical codes of individuals, professions, companies, industries and etc. but there are four fundamental values in media and those are credibility, integrity and civility. In the text below they will be discussed in regards to Media and Media issues. 


\subsection{Credibility}

Today we live in a cruel materialistic world where competitiveness makes individuals and collectives ignore moral values to get or do what they want. This situation is the greatest threat to credibility. Without credibility other moral values mean nothing because credibility makes the foundation for their development. To be credible it means to be trustworthy, it can be said that "credibility is the start point in our actions towards others and towards a full membership to the moral community" (Dej, 2004, s. 28).

It is becoming more common today for the Media to publish or broadcast partial or out of contest information and even false information whether on purpose or by lack of proper research. More than often we have observed titles or announce- ment of news insinuating scandalous and sensationalistic news and when we read or see the information in full context we find out that the title is misleading. Also some Media showing bias in regards to political parties present partial and out of context information about public statement of the rival party in order to manipulate public opinion. Media must be objective. Objectivity can be defined "as characterizing the view which would be agreed upon as a result of argument undeflected by irrelevant considerations', and as 'representing things as they really are'" (Belsey \& Chadwick 2006. pp.83). Objectivity is outmost necessary factor of credibility.

We are more than aware of the Media power on the political opinion but also of the responsibility it has to the public. The Media has to be credible and refrain from doing the previously mentioned violations to the credibility. Striving for sensationalism at all cost will inevitably damage the credibility of the Media outlet in question and make it irrelevant.

\subsection{Integrity}

Like credibility, integrity is also a fundamental moral marker of the Media. Steven Carter (1996, p. 7) defines integrity as "distinguishing good from bad; acting on the basis of the observed difference even at a personal harm; and open discussion to act on the basis of distinguishing good from bad". Integrity is closely related to responsibility meaning that a person of integrity must be ready to take on the responsibility that comes from their actions. Person of integrity will not only say what is right but will make every effort to accomplish the recognition and application of that which they believe to be good or right.

In Media it is difficult to maintain integrity in this form since publishing or broadcasting information at a mediums' harm even if it's the morally right thing to do will inevitably lead to the end of the existence of the medium. 


\subsection{Civility}

We will describe Civility as "the first principle" of morality because it includes the view of self-sacrifice and respect for others (Dej, 2004, s. 30). This same principle is at the very core of all major religions of the world and it is named "Golden rule of humanity" (Küng, 1998, pp. 98-99) by Hans Küng. The "Golden rule of humanity" simply states how to be a better person on an individual level which is where the change needs to happen. With it he represents the common ethical instructions of many great ethical traditions and religions. Here are some of its formulations:

- Confucius (c.551-489 BCE): 'What you yourself do not want, do not do to another person' (Analects 15.23).

- Rabbi Hillel (60 BCE-10 CE): 'Do not do to others what you would not want them to do to you' (Shabbat 31a).

- Jesus of Nazareth: 'Whatever you want people to do to you, do also to them' (Matt.7.12.; Luke 6.31).

- Islam: 'None of you is a believer as long as he does not wish his brother what he wishes himself (Forty Hadith of an-Na-wawi, 13).

- Jainism: 'Human beings should be indifferent to worldly things and treat all creatures in the world as they would want to be treated them- selves' (Sutrakritanga $1,11,33)$.

- Buddhism: 'A state which is not pleasant or enjoyable for me will also not be so for him; and how can I impose on another a state which is not pleasant or enjoyable for me?' (Samyutta Nikaya V, 3 53,3 5- 341,2.).

- Hinduism: 'One should not behave towards others in a way which is unpleasant for oneself: that is the essence of morality' (Mahabharata XIII, 114,8). (Ibid.).

Every journalist, newsperson and all other people that work in Media are just that - people. By accepting the simple Golden rule of humanity and letting it lead our decisions a change for the better can be made. Striving for success and recognition is not a bad thing, we all want it but going for it at all costs is not the right thing. And everyone but an egoist will eventually realize this.

Civility is what makes possibly for as to live as a functional and cohesive society and what makes societal ethical codes mutually acceptable since it lies in their core. Putting it in Media context we can see that civility as respect for others is represented in the media towards their readers and viewers since media depends on them. It is rear however to see civility in the full sense in the Media since as it was previously mentioned Media and journalist strive for sensationalism in order to be more competitive and increase viewer ratings and circulation and for this they sacrifice their civility. It is not wrong to strive to be competitive and successful but it should not be done at all costs, the interest of others should be put into the equation when making our choices. 


\subsection{Responsibility}

It is commonly argued that we as people are reasonable beings and as such we understand the reasons for our actions and their consequences. As such it can be argued that we bare responsibility for our actions. But what does it mean to be responsible? "To be responsible for something is to be answerable for it. What kind of re-sponsibilities do we have? We have prospective responsibilities, the duty to do something, deal with something or take care of something that is in the scope of our particular role for example as a doctor, pilot, solder or parent or the responsibilities we have as moral agents, or as human beings. We have retrospective responsibilities that cover our past actions or failure or refusal to act and the effect of those actions or omissions. Simply said we have causal responsibility, we are responsible for the outcomes of our ac- tions. Such responsibilities are often (but not always) moral or legal responsibilities" (Routledge Encyclopedia of philosophy,1998, p. 7436).

And what is the extent of our retrospective responsibility? As reasonable and logical beings we understand the direct consequences of our actions, which means that we are responsible for the directed intentions of our actions but are we also responsible for the foreseeable outcomes of such actions even though they were not specifically intended? For example if a person shoots a gun at a building not knowing there a people inside is he responsible for the death of those people even though he did not intended to kill someone? Since shooting a gun can possibly harm or kill someone the person shooting is responsible for the outcomes of his actions, such as the death of the people caught in the firing since he could have prevented it but not firing the gun in the first place.

It can be said that the same goes for media. In a case where a person is a victim of a violent crime and the media lead by the pursuit for sensationalism, increase in viewer ratings and circulation, broadcasts or publishes sensitive and personal infor- mation about the victim and specific details of the crime it is likely that that public broadcast will cause harm to the individual in question adding to the previously lived trauma of the crime itself. Should the media be held responsible for the outcome of their actions? The answer is YES. Media industry is run by people and people in general are reasonable so it should be very easy to foresee the outcomes in this case.

What about a situation where we are not directly the cause of an action but we have the power to prevent such action? Does our omission to prevent that action make us responsible for its outcome? For example if a Media outlet comes upon information of vital interest to the public and omitting to publish it will cause harm to group of people, industry or even a society like discovering evidence of embezzling where a board member of the media outlet is involved. Publishing the information is a conflict of interest, will cause a scandal and possible harm to the outlet since the person in- volved is a board member. However omitting to act on the information will cause serious harm to the people, companies and etc from which the 
board member embezzled money. When the crime and information of the media omission is eventually discovered by the authorities should the media outlet be considered responsible as well? Omitting to prevent harm to others should be considered wrong and if there is a possibility to prevent harm such possibility should be considered a moral obligation. Even though there will be unwanted effects on the media outlet in the long run the media will preserve its integrity and credibility.

It can be concluded that we are responsible for the outcomes of the actions that are in our control which means that, "our retrospective responsibilities are partly determined by our prospective responsibilities. ... Such responsibilities, prospective and ret-rospective, flow from a conception of our moral duties and relationships, or are ascribed by a legal system" (Ibid.).

From the discussion above we can observe that as individuals we have responsibilities for our actions, for our omissions and for the outcomes that directly or indirectly result from them. We have responsibilities to ourselves, our friends, family and coworkers, our community, country and the environment. Also as a collective we have the same responsibilities.

\section{MOST COMMON ETHICAL ISSUES IN MACEDONIAN MEDIA}

Publishing of false or unconfirmed information, names or age in pursuit of sensationalistic broadcasting

Sadly, the Macedonian media has a habit of publishing and broadcasting unverified information in order to beat their competitors and be the first to publish the news. In many cases these information have been false and a result of hearsay. There have been many examples of such violations of the credibility and integrity of the media and as such we will present few. These examples will show that in pursuit for competitiveness and sensationalism some media are willing to sacrifice their integrity, credibility and civility.

Example: "In one text, a company is being accused of getting a set tender, including cited statements of representatives of the companies that have not won the tender. Two days later, the same paper published a retraction of the information showing that the mentioned company neither participated in the tender, neither won $i t$. Despite the retraction, other media accepted the false information as a fact on which they built other stories" (Cusidis \& Bojarkovski, 2012, p. 25).

Not respecting the privacy and sorrow of others

There have been many violations of the civility in the Macedonian media. Journalists have been ignoring the rights of the people involved in their reporting. In many cases the full names of victims and suspects of crimes have been reported, speculation and information about the health and privacy as well as vivid photographs 
of accident sites and victims involved have been published and broadcasted without regard for the privacy and sorrow of others.

Example 1 :"When 19 year old D.S. from Kumanovo decided to take her own life, all of Macedonia trough television and the day after in the papers, had the opportunity to learn her full name and surname, to see her photograph, and even hear about the pos- sible motives for her early passing away."(Ibid., p. 26)

Example 2: "Video recordings of the bodies of the drowned tourists from Bulgaria that died in the sinking of the ship "Ilinden" in Ohrid, were labeled as "exclusives" and the TV stations competed with broadcasting more detailed sights of the deceased." (Ibid., pps. 25-26).

Publishing full names or unconfirmed information relating to minors and adults suspects of the crime involving minor, including photographs and names of the child victims.

Example 1: "One TV station with national concession, reporting about a new case of violence and negligence of a child in the village Labunishta near Struga, did not resist the sensationalistic drive - to interview the mother of the victim, to video record the house where the victim resides, the outside and inside of the home, also the little girl itself from the back, whit which it practically revealed its identity to everyone that lives in that place." (Ibid., p. 26).

Example 2: A passage from a report concerning child abuse explaining in detail the act in question and disclosing the name of the suspected offender and the victims. "Yesterday around 16h in the village Morodvis near Kochani, the 37 year old ( full name and surname provided) attacked two girls, minors, and ... intended to with intention to commit fornication. The 11 year I... and her friend $D \ldots$ played in one of the rooms of Ivanas' unfinished house, when B... entered through the window and with a rope tied them to a chair in the kitchen, inflicting minor injuries on their arms. (...) - Ibid., pp. 26-27.

\section{Disregard for the rule of presumption of innocence.}

There have been many instances journalists and media forget about the presumption of innocence and announce information clearly stating the blame of the person arrested without mentioning the fact that that person is just a suspect in an investigation, assuming the role of judge and jury. After news like this the integrity and privacy of the person is totally ruined and any chance of normal life if proven innocent is ruined. It is very rare for journalist to seek confirmation trough multiple sourcis to verify their findings.

\section{Example:}

Almost all the media published the information that "the police in Bi- tola arrested the 32 years old (full name and surname) for dealing drugs". At the same time, many media without criticism transmitted the information ob- tained from the 
police and announced that "the head dealer is arrested", with which the fact that the person in question is only a suspect is forgotten. Often just the charges of the police are not enough so along with the full identity of the person they add qualifications such as "king of the underworld", "monstrous pedophile", "local maniac" and etc. (Ibid., p. 27).

\section{Hate speech and stereotyping about minority or vulnerable groups.}

It is also very often for the media to add ethnic and sexual stereotypes to their reporting adding such labels to everyday events to create more sensationalistic news and increase ratings and circulation. Here we will give few examples of hate speech titles in media which clearly points out to the disregard for use of ethics in Macedonian journalism.

Example 1: "Macedonians don't like junkies, drunks and faggots!"; "Faggots 'adopt- ed' a little boy", "We are asking the Roma not to do gypsy things!" and etc. (Ibid., p. 27).

Example 2: "Children beggers brought back to Albania" - a text in a newspaper that includes the detail about the nationality of the children, also adding the statement that "most commonly children like that, not only beg, but are potential doer of criminal acts" (Ibid., p. 28).

It is very common for Macedonian talk shows to ask callers to comment on current problems discussed in the show and allowing in the process for the callers to "express radical views for the members of the other communities, for the political adversaries or anyone else that doesn't share their opinion" (Ibid.). No matter the party in power we have also been witnesses to the contrary, callers expressing their negative opinion about the party in power and the tv station ending their call.

Hate speech based on ethnic and political grounds.

Among other a common practice is for the media to create news with partisan stereotyping based on their allegiance to the party in power at that given time. In fact, sad as it is, this is everyday occurrence in Macedonia and is tolerated to a great extent. Let's observe some examples:

Example: The division and labeling of "patriots" and "traitors with lists for "executing" with frazezes like: "every Macedonian would be embarrassed by that action", the claim that "he put his capacities to the disposal of the Greek ambassador" and etc. (Ibid.).

\section{RESULT: DECLINE IN THE TRUST IN THE MACEDONIAN MEDIA}

We have been witnesses to many ethical violations in the Macedonian media ranging from disregard of peoples sorrow and privacy, to hate speech, stereotyping 
and disregard for the presumption of innocence as shown in the above discussed examples. The result of such practices has lead to a steady drop in the trust in the Macedonia media. Leading from 2006 when the trust was at a record high $-56,7 \%$ to an all time low this year, $2013-37,4 \%$.

Let's see a comparison trough the years: - In 2006 the trust in the media was measured to be at

$-56,7 \%$ (Klekovski et al., 2006,p. 19),

- In 2007 - 52,6\% (Klekovski \& Krzalovski, 2007, p. 20),

- In 2008 - 53,6\% (Klekovski et al., 2008, p. 11)

- In 2010 - 40,4\% (Klekovski et al., 201, p. 10), and

- In 2013 - 37,4 \% (krzalovski, 2013, p. 8).

It can be said that the pursuit for sensationalism will increase viewer ratings and circulation since people are more interested in shocking and attention grabbing news than every day real world events, but in the long run at least in the Macedonian case it is obvious that it is not a vise policy. Macedonian media are brought down to the level of tabloids becoming more and more a way of entertainment for the simple minds than a trustworthy and reliable news source.

\section{CONCLUSION}

In an ideal world ethics in media will not be a sore subject. It will be easy to observe a situation and provide truthful information to the public in a least harmful manner. In such world journalists', editor's and owner's own personal moral values will make sure that credibility and integrity of the medium is well preserved and own selfish interest will be put aside and other peoples interest will be valued in the decision making. The media will stick to doing their job in the most ethical manner and maintain objectivity at all cost. But we live in a world that is far from perfect.

It is very difficult to speak of ethics in the media. No matter how desirable and crucial it is for the media to be ethical in the end we can't really say that it is possible to fulfill that desire in whole. Media depends on advertisements to make profit and survive and today it's mostly privately owned. This situation makes it difficult for the media to be objective without at least once in a while to run into conflict of interest.

This difficult situation however does not give excuse for Media to be sloppy and publish or broadcast half verified news. Journalists must do their research and make sure their information is verified and credible. Even though manipulation of the public opinion is not approved of, sadly in today's world media has a habit of using it. 
In Macedonia, shown by the previous examples ethics is not a common practice. It's wrong to say that all media and journalists sub come to unethical practices but sadly ethical media is a rare thing. More and more as time goes the people in Macedonia seem to steadily loose trust in the Macedonia media due to the previously mentioned breaches of the most sacred ethical values the credibility, the integrity and the civility of media. Sadly, the Macedonian media has dropped to a tabloid level be- coming unreliable source of information.

Making ethical decisions is difficult as it is at an individual level and that much more difficult at an industry level like the Media where people running it are lead by different interest and are of different personalities. Some may value integrity others may sacrifice it in order to advance their medium or career. In every situation where an ethical dilemma is involved some compromise must be made and decisions may not always be correct or incorrect, but they always must be "well thought out" (Dej, 2004, p. 1).

\section{BIBLIOGRAPHY}

Amstuc, M. R. (2008), International Ethics, Official Gazette, Belgrade (in Serbian). Belsey, A., Chadwick, R. eds. (2006), Ethical issues in journalism and the Media, Routledge, London and NY.

Carter, S. L. (1996), Integrity, Harper perennial, New York.

Causidis, T., Bojarovski, Z. (2012), Newspaper ethics guide, ZHM, Skopje (in Macedonian).

Dej, L. A. (2004), Ethics in the media. Examples and Controversies, Media Center, Belgrade (in Serbian).

Küng, H. (1998), A global ethics for global politics and economics, Oxford University Press, New York, Oxford.

Routledge Encyclopedia of philosophy (1998), Version 1.0, Routledge, London and New York.

Donev, D. (2011), Ethics in journalism, Ukim, Skopje (in Macedonian).

Klekovski, S., Krzalovski, A. (2007), Trust in civil society, MCMS, Skopje (in Macedonian).

Klekovski, S. et al. (2008), Trust in civil society, MCMS, Skopje (in Macedonian).

Klekovski, S. et al. (2006), Trust, responsibility for public needs and issues, MCMS, Skopje (in Macedonian).

Klekovski, S. et al. (2010), Trust in Macedonija, MCMS, Skopje (in Macedonian). Krzalovski, A. (2013, Trust in the meadow and institutions 2013, MCMS, Skopje (in Macedonian). 